\begin{tabular}{|l|l|}
\hline $\begin{array}{l}\text { Postprint } \\
\text { Version }\end{array}$ & 1.0 \\
\hline Journal website & $\underline{\text { http://www.pec-journal.com/article/S0738-3991(11)00368-5/abstract }}$ \\
\hline Pubmed link & $\underline{\text { http://www.ncbi.nlm.nih.gov/pubmed/21807475 }}$ \\
\hline DOI & $10.1016 / j . p e c .2011 .07 .001$ \\
\hline
\end{tabular}

This is a NIVEL certified Post Print, more info at http://www.nivel.eu

\title{
Ten years of EACH (European Association for Communication in Healthcare) and priorities for the next
} ten years.

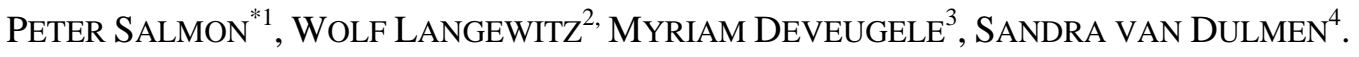 \\ ${ }^{1}$ President. \\ ${ }^{2}$ Past-President. \\ ${ }^{3}$ President-Elect. \\ ${ }^{4}$ Permanent Secretary and Treasurer. \\ *Corresponding author at: Division of Clinical Psychology, University of Liverpool, Whelan Building, \\ Brownlow Hill, Liverpool L69 3GB, United Kingdom. Tel.: +44 151794 5531; fax: +44 1517945537 E- \\ mail address: psalmon@liv.ac.uk (P. Salmon)
}

\section{INTRODUCTION.}

EACH, launched in 2001, has reached its 10th birthday. The organisation's original aims were set out in its articles of association (http://www.each.eu/) and the background to them was explained in the inaugural editorial ${ }^{[1]}$. Our overall aim was to improve the quality of communication in healthcare. The main elements of our strategy were (i) to develop an active network of researchers and teachers and (ii) to promote dialogue and collaboration within and outside this network. We previously reviewed the first five year's work $^{[2]}$. Here we review what each element of our strategy has achieved and what still needs to be done, and we return to our original aims to embolden them for the next decade.

\section{THE EACH NETWORK: WHAT HAS BEEN ACHIEVED?.}

Judged by the extent of its reach across Europe and beyond, EACH has achieved remarkable success. It has become an organisation with more than 300 members across 21 countries in Europe and 10 countries beyond Europe. Of course, EACH reaches many more people than this. Its conferences have attracted over 500 researchers and educators from even more countries. Together with its sister organisation in the USA, $\mathrm{AACH}$, it has an official journal, Patient Education and Counseling, which has steadily grown in its international reach and impact, to become arguably the primary journal for clinical communication research.

The achievements of the research and teaching committees (R-EACH and T-EACH, respectively) have been particularly important because both have worked to build foundations for the development of communication research and education over the next 10 years. R-EACH has invested in the next generation of communication researchers through its residential programme (the Vna workshops) and pre-conference workshops, both of which bring junior communication researchers, selected competitively from open applications, together with experienced faculty. Further demonstrating our commitment to the next generation of researchers, EACH has launched the biennial Jozien Bensing Award for which junior researchers internationally are eligible to compete. T-EACH has established a multiprofessional and multinational network of clinical communication educators from 21 European countries. Active and focused subgroups, coordinated by regular meetings of the whole network, are busy developing teaching and assessment resources, support and networks for clinical communication educators across Europe. 


\section{DIALOGUE AND COLLABORATION: WHAT HAS BEEN ACHIEVED?.}

EACH is a broad college that encompasses quantitative and qualitative researchers with diverse methods, and educators from different backgrounds and different approaches. So EACH has spawned a wide range of collaborations. As well as the many informal collaborations that emerge from conferences and workshops, there are important formal collaborations too. The collaboration that T-EACH has established amongst European educators has reached into countries, particularly in Eastern Europe, that previously had no involvement in EACH. There are exciting research collaborations, too, in which researchers from across Europe and beyond come together under the auspices of EACH. Recently, eight years of work by the Verona Network on Sequence Analysis, including EACH members from nine countries, has culminated in the publication of coding schemes for patient expressions of emotional distress and practitioner responses $[3,4]$.

These are already spawning collaborative and comparative work across Europe. One example is the GULiVer collaborative network in which EACH researchers are identifying and comparing the ways in which practitioners respond to expressions of distress, and the responses that the public prefer, in Belgium, Netherlands, Italy and the UK ${ }^{[5]}$.

\section{WHAT DO WE STILL NEED TO ACHIEVE?.}

We want the network of researchers and educators involved in EACH to be even bigger, and we need to extend the dialogue between them. We do not seek enlargement for its own sake, but because we are aware that there are some groups that we do not yet reach well. For example, researchers in Eastern European countries are not yet well enough represented in EACH; neither are clinical professions other than medicine. Similarly, we do not seek dialogue and collaboration just because it is fun, but because we realise that no single group, and no single model of communication, holds all the answers. So the identity of EACH rests on a scientific approach, by which we do not mean allegiance to a specific kind of datagathering and analysis, but merely the use of evidence, of all kinds, to develop, question and challenge the models, theories, practices and assumptions that define our work. So we need to foster more crossfertilisation of ideas and practices between, on the one hand, clinical communication researchers and educators and, on the other, academic disciplines that have communication at their centre. In particular, we can establish more collaborations with scholars in linguistics, itself a spectrum encompassing approaches from corpus linguistics to sociolinguistics. Given that so many communication dilemmas are moral as much as technical, we need more collaboration with bioethicists, too. Communication can be powerful medicine, with effects that extend beyond the clinical relationship to influence clinical outcomes themselves ${ }^{[6,7]}$. This, in turn, means an expanded concern with physiological aspects of communication ${ }^{[8,9]}$.

As well as researchers and educators, we need to attract more practitioners to become members and attend conferences, too.

They can help us to close the loop between communication research and communication in clinical practice, which would parallel the approach in clinical medicine that assesses effectiveness in practice after efficacy of an intervention has been established. Breaking bad news in oncology illustrates the importance of closing this loop. Paul et al. ${ }^{[10]}$ recently summarised this area of research as very successful in describing communication in clinical practice, partially successful in developing interventions to change practice, but still unsuccessful in finding out whether these interventions help patients! Eggly ${ }^{[11]}$ warned that evidencebased guidance on breaking bad news can be unworkable where it does not take account of clinical reality. We are used to the idea that research and education should improve practice. However, practitioners' active participation in EACH and its activities can ensure that practice improves research and education, too; that is, research and education, while guided by theoretical principles, will be firmly grounded in the realities of clinical practice.

\section{EXTENDING OUR AIMS.}

Ten years ago, and against a general background of medical care that sometimes seemed to neglect the patient when treating the disease, the priority to improve communication was our defining aim. In particular, practitioners needed to concern themselves more with the patients' thoughts, expectations and fears - i.e. be more patient-centred ${ }^{[12]}$. There is still much to do in this way, but there are reasons to extend our aims for the next ten years. First, reflecting the success of communication training in clinical curricula, many practitioners are now much better informed about communication than their predecessors. Many 
practitioners impress communication experts and patients, alike, with their ability to communicate in difficult situations. As communication researchers and educators, we need humility in acknowledging that we may have something to learn from them - as well as them from us ${ }^{[13]}$. Secondly, the last decade has made us aware of complexities in understanding what is 'good communication'. In some ways, the more research we do, the less we realise that we know. For example, some patients, in some circumstances, seem to do better with doctors who are less patient-centred ${ }^{[14]}$, and communication that improves one outcome can worsen another ${ }^{[15]}$. Emotional relationships can exist without any emotional expression ${ }^{[16]}$, and ethical analysis has questioned the foundations on which some communication practices, such as informed choice, are built ${ }^{[17]}$. On the other hand, we now know much more than we did about the mechanisms that link communication to different clinical outcomes, so we know the potential for communication to improve health outcomes at individual and population levels and we have specific targets for our interventions ${ }^{[6]}$. Therefore EACH's mission to improve care needs to mature into an even bigger vision: we seek to exploit the full potential of clinical communication to improve health outcomes, reduce health inequality, and solve the ethical and other dilemmas that practitioners, carers and patients face in modern healthcare.

Achieving these aims will not be through networking and dialogue alone. More research activity and educational development will be needed in many areas. But this in turn depends on research groups and educational teams finding the finance and political support that these developments will need. Moreover, research to demonstrate and understand the links between routine communication and important clinical outcomes will need much larger and more complex - and more expensive - research designs than the relatively small-sample studies that have been common. For example, minor changes in GP communication can achieve benefits for smoking cessation at a population level - but it takes a prospective study on an epidemiological scale to demonstrate this ${ }^{[18]}$. If, as communication researchers and educators, we are to be able to compete for the funding that we will need, governments, public and private health providers and funding organisations have to recognise the potential benefits of communication research and education. So EACH needs to include a new, political priority in its strategy - to raise the profile of clinical communication in European healthcare and healthcare research. We want to achieve a culture in which it is recognised across healthcare that communication is not an optional extra but is central to the concerns of healthcare providers, funders and patients.

\section{REFERENCES.}

[1] Bensing J, van Dulmen S, Kallerup H, Visser A, Borrell F, Finset A, et al. The European Association for Communication in Healthcare. Patient Educ Couns 2001;43:1-4.

[2] van Dulmen S, Finset A, Langewitz W, Zimmermann C, Peltenburg M, Visser A, et al. Five years of EACH (European Association for Communication in Healthcare). Patient Educ Couns 2006;62:379-84.

[3] Zimmermann C, Del Piccolo L, Bensing J, Bergvik S, De Haes H, Eide H, et al. Coding patient emotional cues and concerns in medical consultations: the Verona coding definitions of emotional sequences (VRCoDES). Patient Educ Couns 2011;82:141-8.

[4] Del Piccolo L, de Haes H, Heaven C, Jansen J, Verheul W, Bensing J, et al. Development of the Verona coding definitions of emotional sequences to code health providers' responses (VR-CoDES-P) to patient cues and concerns. Patient Educ Couns 2011;82:149-55.

[5] Moretti F, van Vliet L, Bensing J, Deledda G, Mazzi M, Rimondini M, et al. A standardized approach to qualitative content analysis of focus group discussions from different countries. Patient Educ Couns 2011;82:420-8.

[6] Street Jr RL, Makoul G, Arora NK, Epstein RM. How does communication heal? Pathways linking clinician-patient communication to health outcomes. Patient Educ Couns 2009;74:295-301.

[7] Bensing JM, Verheul W. The silent healer: the role of communication in placebo effects. Patient Educ Couns 2010;80:293-9.

[8] Finset A, Graugaard PK, Holgersen K. Salivary cortisol response after a medical interview: the impact of physician communication behaviour, depressed affect and alexithymia. Patient Educ Couns 2006;60:11524.

[9] Hulsman RL, Pranger S, Koot S, Fabriek M, Karemaker JM, Smets EM. How stressful is doctor-patient communication? Physiological and psychological stress of medical students in simulated history taking and bad-news consultations. Int J Psychophysiol 2010;77:26-34.

[10] Paul CL, Clinton-McHarg T, Sanson-Fisher RW, Douglas H, Webb G. Are we there yet? The state of the evidence base for guidelines on breaking bad news to cancer patients. Eur J Cancer 2009;45:2960-6. 
Salmon, P., Langewitz, W., Deveugele, M., Dulmen, S. van. Ten years of EACH (European Association for Communication in Healthcare) and priorities for the next ten years. Patient Education and Counseling: 2011 85(1), 1-3

[11] Eggly S, Penner L, Albrecht TL, Cline RJW, Foster T, Naughton M, et al. Discussing bad news in the outpatient oncology clinic: rethinking current communication guidelines. J Clin Oncol 2006;24:716-9.

[12] Bensing J. Bridging the gap. The separate worlds of evidence-based medicine and patient-centered medicine. Patient Educ Couns 2000;39:17-25.

[13] Kleinman A. Moral experience and ethical reflection: can ethnography reconcile them? A quandary for the new bioethics. Daedalus 1999;128:69-97.

[14] Graugaard PK, Eide H, Finset A. Interaction analysis of physician-patient communication: the influence of trait anxiety on communication and outcome. Patient Educ Couns 2003;49:149-56.

[15] Kinmonth AL, Woodcock A, Griffin S, Spiegal N, Campbell MJ. Randomised controlled trial of patient centred care of diabetes in general practice: impact on current wellbeing and future disease risk. Brit Med J 1998;317:1202-8.

[16] Young B, Ward J, Forsey M, Gravenhorst K, Salmon P. Examining the validity of the unitary theory of clinical relationships: comparison of observed and experienced parent-doctor interaction. Patient Educ Couns 2010.

[17] O'Neill O. Autonomy and trust in bioethics. Cambridge: Cambridge University Press; 2002.

[18] Stead L, Bergson G, Lancaster T. Physician advice for smoking cessation. Cochrane Database Syst Rev 2008;CD000165. 